\title{
Quantos são os Livros Teóricos de Turismo Publicados no Brasil? Uma Análise da Produção Bibliográfica Nacional (1990-2010)
}

\author{
How many are the tourism theoretical books published in Brazil? An analysis of national \\ bibliographic production (1990-2010)
}

\author{
Alexandre Panosso Netto ${ }^{1}$ \\ Guilherme Farinazzo de Mello Calciolari ${ }^{2}$
}

\section{Resumo}

O presente estudo pretende analisar a produção científica em turismo no Brasil publicada em forma de livro por 51 editoras nacionais no período de 1990 a 27 de agosto de 2010. Os dados foram coletados nos sites das editoras e a análise se ateve aos seguintes aspectos: quantidade de livros publicados por cada uma das editoras investigadas; número de livros publicados por ano no período 1990 e 2010 (até 25 de agosto); número de edições que os livros em turismo alcançam e; temática abordada nos livros. Concluiu-se que a publicação de livros de turismo no Brasil está em ritmo decrescente desde 2002 e que está na raiz deste fato a diminuição da oferta de cursos superiores de turismo no país.

Palavras-chave: turismo; livros; educação; editoras; Brasil.

\begin{abstract}
The present study analyzes the scientific production in tourism in Brazil published in book form for 34 national publishing houses in the period of 1990 to August, 27th of 2010. The data had been collected in the sites of the publishing houses and the analysis if it abided by the following aspects: amount of books published for each one of the investigated publishing companies; book number published per year in period 1990 and 2010 (up to August 25th); edition number that the books in tourism reach and; thematic boarded in books. One concluded that the book publication of tourism in Brazil is in decreasing rhythm since 2002 and the reasons of this fact are a conjunction of factors that the principal is the reduction of offer of superior programs of tourism in the country.
\end{abstract}

Keywords: tourism; books; education; publishing houses, Brazil.

\footnotetext{
${ }^{1}$ Prof. Dr. do Curso de Graduação em Lazer e Turismo e do Mestrado em Estudos Culturais da Escola de Artes, Ciências e Humanidades da Universidade de São Paulo (EACH-USP). Integrante do grupo de pesquisa em Pesquisa, Educação e Formação Profissional em Turismo e Hospitalidade da EACH-USP. Email: panosso@usp.br.

${ }^{2}$ Acadêmico do curso de Lazer e Turismo da Escola de Artes, Ciências e Humanidades da Universidade de São Paulo (EACH-USP). Integrante do grupo de pesquisa em Pesquisa, Educação e Formação Profissional em Turismo e Hospitalidade da EACH-USP. Email: guilherme.calciolari@usp.br.
} 


\section{Introdução}

O desenvolvimento de qualquer área científica está diretamente relacionado, dentre outros fatores, com a quantidade e, principalmente, com a qualidade da pesquisa feita e publicada em tal área. Gradativamente, o conhecimento produzido passa por revisões e refutações, sendo testado e aprimorado, na tentativa de estabelecer a sua validade e utilidade. Neste sentido, o objetivo do presente artigo é analisar como está caracterizada a produção científica de turismo no Brasil publicada em forma de livro e estabelecer um panorama a partir do qual os autores, editores, acadêmicos, profissionais, professores e demais interessados no turismo possam situar-se entre as diversas publicações e escolas temáticas existentes.

O incentivo para escrever e analisar as publicações de turismo no Brasil surgiu da observação que o número de estudos e de livros sobre turismo cresceu, principalmente no início da década de 2000. A proposta se ateve a 51 editoras que publicaram livros teóricos de turismo. Não foram analisados os livros considerados guias turísticos, relatos de viagens, guias de conversação em línguas estrangeiras, livros de receitas, histórias culturais de receitas, livros que ensinam coquetéis, drinks e pratos típicos, folhetos, folders e revistas de divulgação de destinos. Os livros considerados na análise são os que abordam, sob uma perspectiva teórica, técnica e científica, aspectos do turismo. Basicamente são livros que se fundamentam em outras ciências, campos ou teorias do conhecimento humano, tais como sociologia, antropologia, filosofia, teoria de sistemas, urbanismo, administração, economia, estatística, técnicas e métodos de planejamento entre outros.

Justifica-se o presente estudo, pois sendo o turismo uma área relativamente importante no Brasil, faz-se necessário estudar a sua produção bibliográfica para que se desenvolvam trabalhos que avancem rumo a uma prática de construção de conhecimentos científicos e não apenas uma reprodução de conhecimentos que já foram construídos. Esta pesquisa visa também servir como guia para que o conhecimento em turismo avance e seja constantemente revisado. A partir das ponderações feitas espera-se que seja possível fornecer subsídios e base teórica para estimular entre os pesquisadores o interesse pela compreensão e análise da produção científica nacional neste campo. 


\section{Um Pouco de Teoria}

Desde 1971, quando foi implantado o primeiro curso de graduação em turismo no Brasil, estudantes e professores da temática têm destacado a pouca produção científica neste campo de estudos. Deste modo, o primeiro estudo específico sobre o tema foi o de Barretto (1996), intitulado "Produção bibliográfica em turismo no Brasil". Passando pelos temas do livro no Brasil, a relação entre o livro e a escola, o mercado editorial, os leitores e o problema do preço e da reprografia, a autora chega ao ponto fundamental de seu estudo, qual seja: os livros de turismo de autores brasileiros. Consultando bibliotecas de universidades que tinham acervo de turismo; no sistema Unibibli em CD-Rom que reunia os acervos da USP, Unesp e Unicamp; em seu acervo próprio e em levantamentos feitos via fax junto às editoras, a autora encontrou 66 livros “desses, 31 foram editados entre 1970 e 1980 e de 4 não foi possível estabelecer a data. Apenas 15 foram editados na década de 80, e 23 entre 1990 e 1996" (BARRETTO, 2006, p. 99).

Sobre as editoras à época, Barretto (1996) destacou que as que tinham títulos disponíveis sobre turismo eram a Ática, CTI/Terra, Hucitec, Kosmos, Loyola, Papirus, Educs, USP e Senac, sendo as últimas três editoras não-comerciais.

Há 14 anos a pesquisadora havia identificado um problema que ainda hoje é recorrente no Brasil: a pouca quantidade de livros técnicos e teóricos acadêmicos sobre turismo. Apontou também que alguns bons títulos publicados na década de 1970 e 1980 "estão esgotados e não se cogita reedição, apesar de sua alta qualidade...” (BARRETTO, 1996, p.99).

Os primeiros estudantes de turismo, frente ao modesto número de publicações nacionais, utilizavam estudos de autores estrangeiros, a experiência dos professores, documentos oficiais sobre turismo e a própria experiência para seus insights e análises. É importante lembrar que sem a internet a "garimpagem" dos textos era bem mais lenta do que nos dias atuais. Pode-se afirmar que esse cenário permaneceu, com poucas alterações, durante as décadas de 1970, 1980 (conforme atesta o estudo de Barretto [1996]) e passou a mudar somente no início dos anos 1990. Desse fato vem uma opinião errada de alguns autores e estudantes brasileiros de que “existe pouca produção científica em turismo". Pode até ser que exista pouca produção disponível no Brasil, mas internacionalmente esse volume é grande, praticamente impossível de ser quantificado. 
Sobre esse tipo de investigação científica que analisa o conhecimento de uma determinada área, quantificando-o, denomina-se bibliometria. Bufrem e Prates (2005) dissertam acerca dos diferentes estudos feitos por meio de métodos quantitativos a fim de analisar a produção científica em um determinado âmbito e afirmam também que os estudos bibliométricos têm por objeto de estudo livros, documentos, revistas, artigos e autores. Suas variáveis são os números de empréstimos (circulação) e de citações e também a freqüência de extensão de frases. Os métodos são: ranking, freqüência e distribuição. Tudo isso visa à correta alocação de recursos, pessoas, tempo e dinheiro (BUFREM e PRATES, 2005).

Vanti (2002), por sua vez, discute os usos da bibliometria em termos genéricos. Os que mais se aplicam à pesquisa são: identificar as tendências e o crescimento do conhecimento em uma área; prever as tendências de publicação; estudar a dispersão e a obsolescência da literatura científica; medir o grau e padrões de colaboração entre autores; analisar os processos de citação e co-citação; avaliar a circulação e uso de documentos em um centro de documentação e por último, medir o crescimento de determinadas áreas e o surgimento de novos temas.

Além da bibliometria, já definida, existe a cientometria e a infometria, sendo que

A cientometria preocupa-se com a dinâmica da ciência, como atividade social, tendo como objetos de análise a produção, a circulação e o consumo da produção científica. A infometria, por sua vez, abarca as duas primeiras, tendo desenvolvido métodos e ferramentas para mensurar e analisar os aspectos cognitivos da ciência. (SANTOS e KOBASHI, 2009, p. 159)

A cientometria se diferencia por estudar disciplinas assuntos, campos científicos e tecnológicos, patentes, dissertações e teses. Faz a análise de conjunto de correspondência, coocorrência de termos, expressões e palavras-chave através das variáveis dos fatores que diferenciam as subdisciplinas e também de acordo com a comunicação dos cientistas. A cientometria tem por objetivo identificar domínios de interesse e compreender como e quanto os cientistas se comunicam (BUFREM e PRATES, 2005).

Além dessas formas de análise, Vanti (2002) e Bufrem e Prates (2005) apresentam a webmetria (ou webometria), que tem como objeto de pesquisa a quantificação da informação, tecnologia e aspectos do conhecimento que estão disponíveis na web. 
No âmbito próprio da bibliometria destacam-se três principais leis: lei de Bradford, lei de Lotka e leis de Zipf. A primeira, de Bradford,

sugere que na medida em que os primeiros artigos sobre um novo assunto são escritos, eles são submetidos a uma pequena seleção, por periódicos apropriados, e se aceitos, esses periódicos atraem mais e mais artigos, no decorrer do desenvolvimento da área de assunto. (GUEDES e BORSCHIVER, 2005, p. 4)

Assim essa lei é útil no que se diz respeito ao desenvolvimento de políticas de aquisição e de descarte de periódicos - principal foco de estudo da lei.

A lei de Lotka estuda os autores propriamente ditos e basicamente diz que "quanto mais solidificada estiver uma ciência, maior probabilidade de seus autores produzirem múltiplos artigos, em dado período de tempo" (GUEDES e BORSCHIVER, 2005, p. 5).

A terceira lei é a que mais se aplica à pesquisa aqui apresentada - a lei de Zipf - pois se relaciona às citações diretas ou indiretas, ou seja, a indexação automática entre textos. Essa lei explica matematicamente como tais citações podem ser contabilizadas e estudadas. Há ainda outras leis e princípios que servem de apoio à bibliometria. Por exemplo, a frente de pesquisa estuda "por meio de um conjunto de autores, que se citam na literatura recente, revelando um estreito padrão de relações múltiplas, na literatura sobre o assunto" (GUEDES e BORSCHIVER, 2005, p. 11).

Bastante útil também para esta pesquisa é o acoplamento bibliográfico, que por meio das citações estima o grau de ligação entre dois textos ou mais. E por fim, a teoria epidêmica de Goffman que tem a capacidade de estimar a razão do crescimento ou declínio de determinada área do conhecimento (GUEDES e BORSCHIVER, 2005).

\section{O que Mostra a Prática}

Os primeiros dados da pesquisa foram obtidos consultando os sites das editoras entre os dias 01 de novembro e 12 de dezembro de 2008. Posteriormente, uma atualização foi feita entre os dias 20 e 27 de agosto de 2010, motivada pela eminente publicação do estudo. Destaca-se que nem todas as editoras mantêm seus sites atualizados ou com informações completas. Algumas 
apresentam a edição do livro, mas não apresentam a data da publicação da primeira edição. Nesses casos foi necessário consultar outros sites de livrarias ou os próprios livros disponíveis na biblioteca da Escola de Artes, Ciências e Humanidades da Universidade de São Paulo (EACH-USP) e no acervo pessoal dos autores

Vários são os livros de turismo que foram publicados nas décadas de 1960 a 1980. Para confirmar essa informação recomenda-se a consulta ao site da Fundação Biblioteca Nacional (www.bn.br) e ao estudo já referido de Barretto (1996), todavia a análise aqui se detém apenas às editoras que publicaram livros de turismo após o ano de 1990. Desta forma, livros publicados antes dessa data ficaram fora da análise, com exceção do livro "Turismo: atividade marcante no século XX”, publicado em 1986 pela Educs, e ampliado e revisto em edições posteriores durante a década de 1990.

No site da Fundação Biblioteca Nacional, já apontado, em consulta feita em maio de 2007, foi possível levantar o número de 583 livros depositados que trazem como assunto o turismo (PANOSSO NETTO, 2007). Em consulta recente, para revisão desse artigo, em 25 de agosto de 2010, esse número de livros havia subido para 674 títulos. Se for levado em consideração que por lei a editora ou o editor devem entregar um exemplar dos livros publicados à Biblioteca Nacional (Lei $n^{0} 10.994$, de 14/12/2004) então se conclui que a publicação de livros sobre turismo no Brasil ainda está incipiente, frente ao número de cursos superiores em turismo (586, segundo dados publicados pelo INEP/MEC em 2009 com coleta feita em 2007) e frente às imensas análises e possibilidade de investigação que o fenômeno turístico oferece (Tabela 1).

Tabela 1 - Número de cursos de graduação presenciais na área de viagens, turismo e lazer por categoria administrativa da IES em 2007
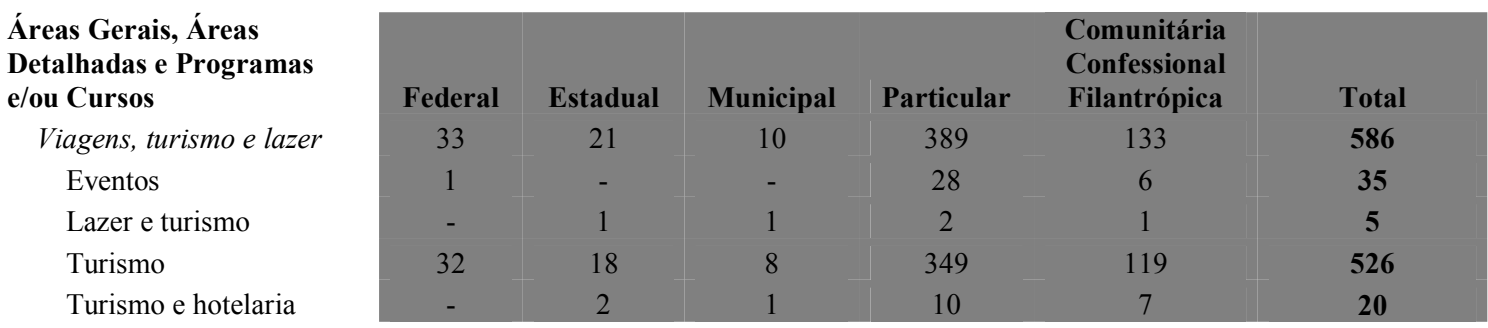

Fonte: MEC/Inep/Deed (2007), disponível em: < http://www.inep.gov.br/superior/censosuperior/sinopse/>. 
Outro ponto relevante é o fato de que os livros de turismo muitas vezes não estão corretamente classificados nos sites das editoras. Por exemplo, livros de história da alimentação ou de idiomas estrangeiros podem ser encontrados na categoria "turismo".

O aumento dos cursos de turismo (e o aumento do mercado consumidor de livros da área, a partir de 1994 no Brasil) foi o principal fator que influenciou as editoras nacionais a publicarem livros sobre o tema. Essa constatação foi feita também pelo Jornal Folha de São Paulo em 2002, ao publicar reportagem de Valle (29/04/2002) quando afirmou que "acompanhando o crescimento da indústria do turismo e de cursos na área, o mercado editorial de livros técnicos de turismo vive um boom de lançamentos.” E continua:

Não é preciso voltar tanto no tempo para constatar o quanto o setor cresceu. Em 1990, havia 27 cursos de turismo no Brasil e 5.739 estudantes do ramo, números que hoje [2002] subiram, respectivamente, para 230 e 37.906, de acordo com o MEC (Ministério da Educação e Cultura). (VALLE, 2002)

Constata-se o fato relatado facilmente, pois em 1994 apenas duas editoras publicavam sistematicamente livros de turismo, Educs e Papirus (em 1996 eram 9 segundo Barretto ([1996]). Dez anos depois, em 2004, esse número chegava a 38. Em 2010 já eram 51 editoras que haviam publicaram algum livro na área.

A primeira pesquisa, divulgada por um dos autores deste artigo em 2005 (PANOSSO NETTO, 2005), trabalhou com dados de 17 editoras nacionais, num total de 329 títulos. A segunda, de 2007 (PANOSSO NETTO, 2007), ampliou a amostra e trabalhou com 27 editoras, num total de 460 títulos. A terceira foi aumentada novamente e trabalhou com amostra de 34 editoras que haviam publicaram juntas 493 livros de turismo entre os anos 1990 e 2008 (CALCIOLARI e PANOSSO NETTO, 2009). A atual pesquisa considera 51 editoras que publicaram 560 títulos (com dados coletados até 27 de agosto de 2010) um aumento de exatos $300 \%$ em cinco anos no número de editoras, mas de apenas $41,25 \%$ no número de livros.

$\mathrm{Na}$ Tabela 2 estão as editoras selecionadas para a investigação. Na frente do nome da editora consta o ano em que ela passou a publicar em turismo e o ano em que teve seu último lançamento nesta área (período de análise 1990 até 27 de agosto de 2010). 
Tabela 2 - Relação de editoras investigadas

\begin{tabular}{|c|c|}
\hline Editora & $\begin{array}{c}\text { Período em que publica/ou } \\
\text { em turismo }\end{array}$ \\
\hline Aleph & 2000 a 2010 \\
\hline Anhembi Morumbi & 2005 a 2010 \\
\hline Aprenda fácil & 2000 a 2001 \\
\hline Asselvi & 2001 a 2003 \\
\hline Atlas & 2000 a 2008 \\
\hline Átomo e Alínea & 2002 a 2010 \\
\hline Autêntica & 1998 a 2004 \\
\hline Bookman & 2000 a 2010 \\
\hline Cabral & 2002 a 2005 \\
\hline Campus & 2000 a 2009 \\
\hline Casa da Qualidade & 1995 a 2001 \\
\hline Chronos & 2000 a 2003 \\
\hline Contexto & 2000 a 2003 \\
\hline Edicon & 2001 a 2005 \\
\hline Educs & 1986 a 2010 \\
\hline Edunisc & 2002 a 2005 \\
\hline Edusc & 2000 a 2005 \\
\hline Futura & 1998 a 2004 \\
\hline Hucitec & 1996 a 2002 \\
\hline Manole & 1999 a 2010 \\
\hline Papirus & 1990 a 2007 \\
\hline Protexto & 2004 (somente) \\
\hline Qualitymark & 1997 a 2008 \\
\hline Rima & 2007 e 2009 \\
\hline Roca & 2000 a 2007 \\
\hline Saraiva & 2003 a 2008 \\
\hline Senac Nacional & 1999 a 2008 \\
\hline Senac São Paulo & 1996 a 2009 \\
\hline Textonovo & 2003 a 2005 \\
\hline Thomson Pioneira & 1998 a 2008 \\
\hline UCDB & 2001 a 2004 \\
\hline UFBA & 2003 a 2006 \\
\hline UFMG & 2005 (somente) \\
\hline UniverCidade & 2002 a 2008 \\
\hline Érica & 2010 (somente) \\
\hline Letras Jurídicas & 2008 (somente) \\
\hline Garamond & $2005-2006$ \\
\hline IBPI PRESS & 2000 (somente) \\
\hline Verbo & 2003 (somente) \\
\hline EdUFSCAR & 2009 (somente) \\
\hline Valer & 2008 (somente) \\
\hline Juruá & 2004 e 2007 \\
\hline EDIPRO & 2003 (somente) \\
\hline Renovar & 2005 (somente) \\
\hline Ícone & $2001-2010$ \\
\hline
\end{tabular}




\begin{tabular}{|c|c|}
\hline Almedina & $2003-2007$ \\
\hline Mercado Aberto & 2002 (somente) \\
\hline Contra Capa & 2002 (somente) \\
\hline UNB & 2001 (somente) \\
\hline Ática & 1992 (somente, com várias \\
& edições do livro) \\
\hline Pearson & $2004-2009$ \\
\hline
\end{tabular}

Fonte: dados da pesquisa

Das 51 editoras que foram analisadas, somente seis entraram no mercado de turismo após 2004: Saraiva, Érica, Garamond, EdUFSCAR, Juruá e Pearson.

Algumas editoras publicaram somente em um ano livros de turismo, são elas: Editora da UFMG (2005), Érica (2010), IBPI PRESS (2000), Verbo (2003), EdUFSCAR (2009), Valer (1998), EDIPRO (2003), Renovar (2005), Mercado Aberto (2002), Contra Capa (2002), UNB (2001), Protexto (2004), Letras Jurídicas e Ática (1992).

Um dado preocupante é que entre as 51 editoras, verifica-se que 14 publicaram somente em um ano, ou seja, não há uma continuidade ou série histórica de publicação (excetuando-se a Érica que publicou somente em 2010 e por isso não se pode afirmar que não tenha continuidade).

Outro dado que chama a atenção é que das 23 editoras que já haviam publicado antes do ano 2000 (inclusive), somente 5 continuaram publicado até o ano de 2010, sendo elas a Aleph, Bookman, Educs, Manole e Senac São Paulo (esta última teve ao menos um livro de turismo lançado em setembro de 2010, data posterior à coleta de dados, por isso foi computada). Além do mais, das 51 editoras, somente 7 publicaram algum título em 2010. Ou seja, há crescente desinteresse das editoras em publicar na área.

Como se trata do resultado parcial de uma investigação mais completa, foi analisado o número de livros publicados por ano, levando-se em conta editoras, ano de publicação, número de edições ou revisões/ampliações e em que área do turismo a publicação se encaixa. No relatório completo do estudo, estão relacionados todos os livros publicados bem como os seus autores. Por conter dezenas de páginas, esses dados de títulos dos livros e autores não serão aqui descritos. 


\section{Análise dos Dados}

Os primeiros dados do Gráfico 1 dizem respeito às editoras investigadas e o número de livros de turismo publicados por cada uma. A que tem o maior número de títulos em turismo é a Aleph, com 64 títulos. Onze publicaram somente um título, sendo que 26 publicaram 4 títulos ou menos cada uma.

Nesses dados também foram inseridas editoras menores, que têm apenas um livro publicado, como Rima e Editora da Universidade Federal de Minas Gerais. As editoras universitárias também estão nessa lista, porém o número de livros publicados por elas é pequeno, com exceção da EDUSC. Destaca-se que entre as dez maiores em número de títulos publicados, oito têm sua sede no Estado São Paulo (Aleph, Roca, Manole, Papirus, Atlas, Senac São Paulo, Contexto e Thomson Pioneira).

É evidente que o mercado acompanhou o crescimento do número de cursos de graduação em turismo no país, chegando a seu ápice em 2002, com um total de 97 títulos publicados, e caindo gradativamente até agosto de 2010, sem previsão de retomada de crescimento, pois não há indicadores para isso. Destaca-se que é no período de 2002 a 2008 que ocorre uma grande redução da oferta dos cursos de turismo no Brasil, conforme previram inúmeros estudiosos brasileiros, entre eles Mario Jorge Pires, que afirmou à Valle (2002) na mesma reportagem da Folha de São Paulo já citada:

"Muitos dos cursos não vão se sustentar e acabarão fechando. Há escolas que nem deveriam funcionar", afirma Mário Jorge Pires, coordenador do curso de turismo da ECA (Escola de Comunicações e Artes), da USP. Na opinião dele, a regra também vale para os editores de turismo: os mais fracos perderão espaço. (VALLE, 2002) 
Gráfico 1 - Editoras e quantidade de livros publicados

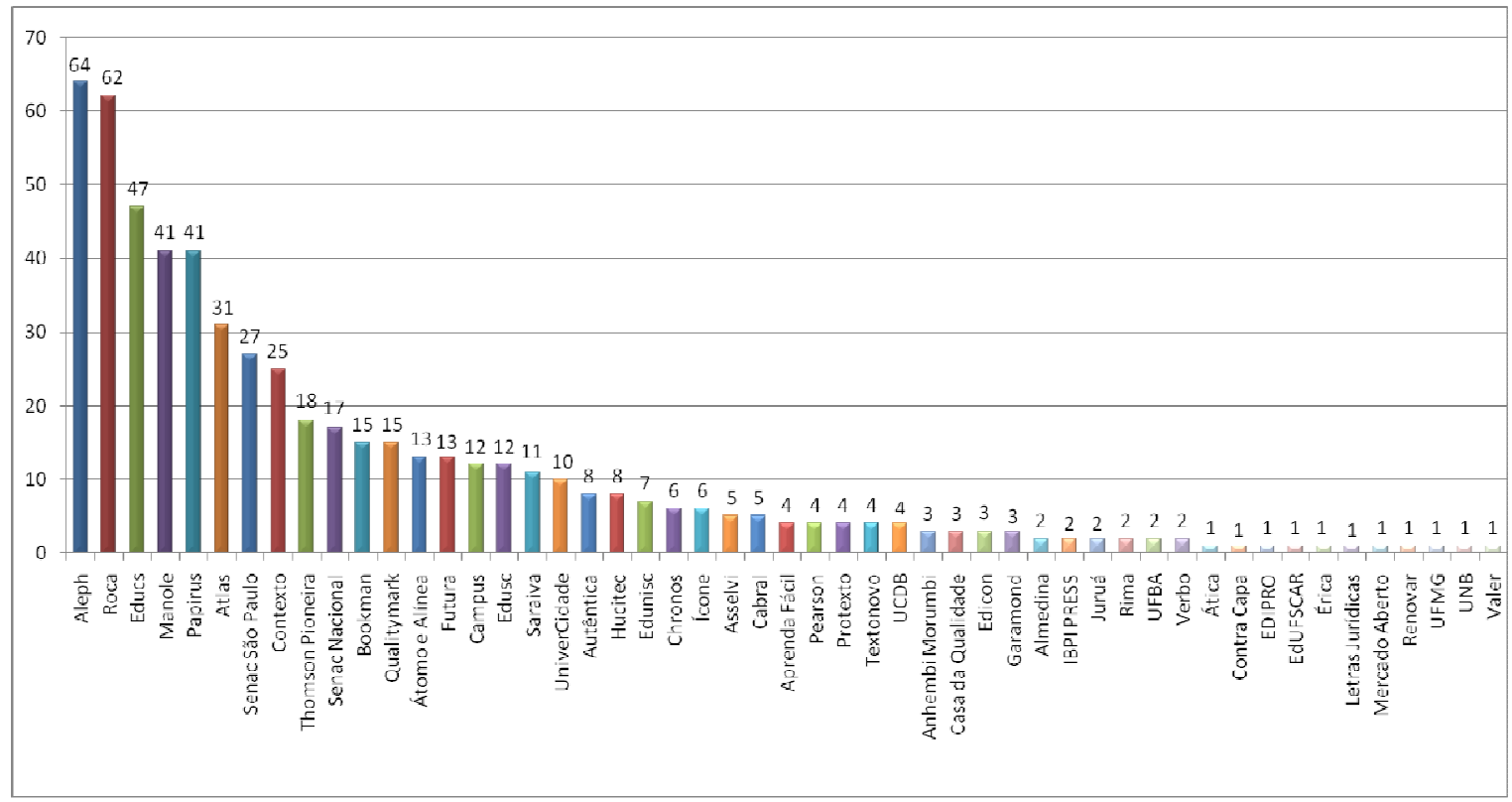

A tendência mostrada no Gráfico 2 é de que a queda de títulos publicados pode estar chegando ao seu limite. De acordo com a nova reestruturação e diretrizes de turismo, novos cursos estão sendo oferecidos, principalmente pelas instituições de ensino públicas, bem como os cursos de pós strito senso estão se fortalecendo, fatores que podem levar a uma retomada de publicações na área, mesmo que seja tímida.

Esse fato de poucas editoras no momento estarem interessadas em publicar livros de turismo reflete-se na criação de uma demanda reprimida de autores que possuem trabalhos prontos para publicação, mas não conseguem ter tais trabalhos aceitos. Nesse sentido, pode ocorrer uma procura por editoras que, mediante pagamento dos custos de edição, publicam a obra. Outra saída é o autor transformar seu livro em artigos e assim publicar em revistas científicas da área ou apresentar seus estudos em congresso científicos.

Gráfico 2 - Número de livros publicados por ano (1990 a 27 de agosto de 2010) 


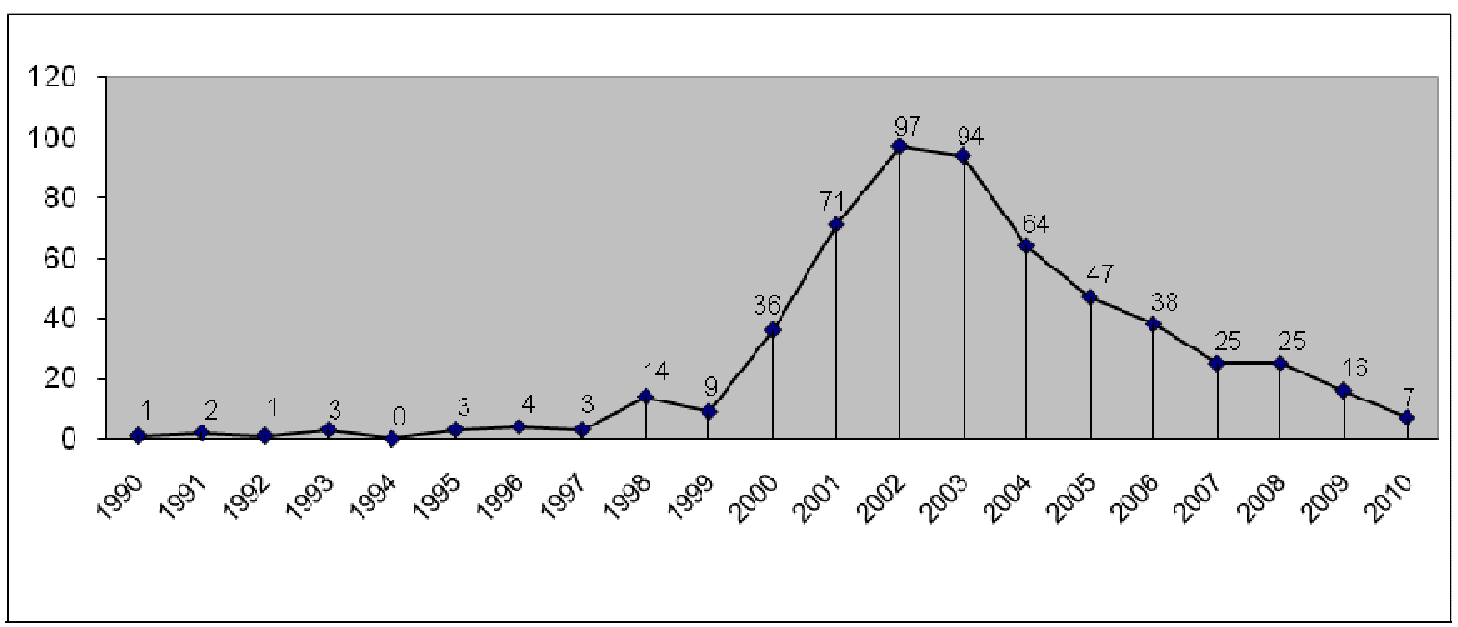

Fonte: Dados da pesquisa

Sobre a qualidade dos livros publicados torna-se difícil tirar conclusões, todavia, o número de edições ou tiragens de uma obra revela se ela é aceita ou não pela comunidade acadêmica. Neste sentido, a pesquisa levantou também as edições em que se encontram os livros publicados.

De acordo com a Fundação Biblioteca Nacional (www.bn.br) reedição de um livro significa "nova impressão com alteração no conteúdo/texto da publicação" e reimpressão "a nova impressão da obra sem qualquer alteração no texto/conteúdo." Assim sendo, somente a Atlas e a Átomo e Alínea consideram, de forma correta, uma nova tiragem de livros como reimpressão. As demais editoras analisadas consideram uma reimpressão como nova edição, ou reedição. Assim, livros que são apresentados na $2^{\mathrm{a}}, 3^{\mathrm{a}}, 4^{\mathrm{a}}$ edição, e assim por diante, na verdade estão na $2^{\mathrm{a}}, 3^{\mathrm{a}}$ e $4^{\mathrm{a}}$ reimpressão ou tiragem. Para padronizar a análise, cada tiragem/reimpressão dos livros da Atlas e Átomo e Alínea foram consideradas novas edições. Exemplo: o livro que está na $1^{\mathrm{a}}$ edição, mas na $2^{\mathrm{a}}$ tiragem, foi considerado na $2^{\mathrm{a}}$ edição; o livro que está na $2^{\mathrm{a}}$ edição, $3^{\mathrm{a}}$ tiragem, foi considerado na $4^{\mathrm{a}}$ edição $\left(1^{\mathrm{a}}\right.$ edição mais três tiragens da $2^{\mathrm{a}}$ edição) e assim por diante. Destaca-se ainda que 5 livros analisados não informam o ano de publicação.

Entre os livros selecionados, somente 117 , ou 20,9\% dos 560 tiveram uma segunda edição ou mais. Além disso, apenas $12 \%$ dos alcançaram três ou mais edições, conforme tabela. 
Tabela 3 - Número de edições dos livros

\begin{tabular}{|l|r|r|}
\hline $\begin{array}{l}\text { Número da } \\
\text { edição }\end{array}$ & $\begin{array}{l}\text { Número de } \\
\text { livros }\end{array}$ & Porcentagem \\
\hline $1^{\mathrm{a}}$ & 443 & $79,1 \%$ \\
\hline $2^{\mathrm{a}}$ & 50 & $8,9 \%$ \\
\hline $3^{\mathrm{a}}$ & 29 & $5,2 \%$ \\
\hline $4^{\mathrm{a}}$ & 11 & $1,9 \%$ \\
\hline $5^{\mathrm{a}}$ & 6 & $1 \%$ \\
\hline $6^{\mathrm{a}}$ & 2 & $0,3 \%$ \\
\hline $7^{\mathrm{a}}$ & 8 & $1,4 \%$ \\
\hline $8^{\mathrm{a}}$ & 1 & $0,2 \%$ \\
\hline $9^{\mathrm{a}}$ & 5 & $0,9 \%$ \\
\hline $10^{\mathrm{a}}$ & 0 & $0 \%$ \\
\hline $11^{\mathrm{a}}$ & 2 & $0,3 \%$ \\
\hline $12^{\mathrm{a}}$ & 0 & $0, \%$ \\
\hline $13^{\mathrm{a}}$ & 1 & $0,2 \%$ \\
\hline $14^{\mathrm{a}}$ & 1 & $0,2 \%$ \\
\hline $15^{\mathrm{a}}$ & 0 & $0 \%$ \\
\hline $16^{\mathrm{a}}$ & 0 & $0 \%$ \\
\hline $17^{\mathrm{a}}$ & 1 & $0,2 \%$ \\
\hline Total & $\mathbf{5 6 0}$ & $\mathbf{1 0 0 \%}$ \\
\hline Font & & 0 \\
\hline
\end{tabular}

Fonte: dados da pesquisa

Tais dados mostram a limitação desse mercado e levantam algumas hipóteses como origem, que pode ser o desinteresse dos alunos pela leitura, o preço, a dificuldade de acesso à leitura e até mesmo pela dúvida acerca da qualidade dos livros publicados.

Com o aprofundamento da pesquisa, sentiu-se a necessidade de ampliar as temáticas dos livros e assim foi feita uma segmentação de tema a fim de deixar mais claro o panorama das publicações. Foram consideradas 41 grandes áreas, sendo elas: meios de hospedagem, manual, planejamento e desenvolvimento, administração/gestão, crítica e reflexão, eventos, meio ambiente, marketing, alimentos e bebidas, cultura e patrimônio, legislação, ecoturismo, economia, lazer, anais de eventos, agenciamento, educação e formação, hospitalidade, transportes, história, turismo rural, animação e recreação, comunicação, geografia, sociologia, política, antropologia, metodologia científica, entretenimento, estatística, psicologia, turismo religioso, contabilidade, ética, filosofia, segmentação, terceira idade, turismo de aventura, GLS, turismo urbano e outros. O número de livros de cada temática está na Tabela 4.

Tabela 4 - Áreas em que os livros foram publicados 


\begin{tabular}{|c|c|}
\hline Área classificada & $\begin{array}{l}\text { Número de } \\
\text { livros }\end{array}$ \\
\hline Meios de hospedagem & 72 \\
\hline Manual & 47 \\
\hline $\begin{array}{l}\text { Planejamento e } \\
\text { desenvolvimento }\end{array}$ & 46 \\
\hline Administração/gestão & 40 \\
\hline Crítica e reflexão & 32 \\
\hline Meio ambiente & 31 \\
\hline Eventos & 30 \\
\hline Legislação & 26 \\
\hline Marketing & 25 \\
\hline Cultura e patrimônio & 23 \\
\hline Ecoturismo & 22 \\
\hline Alimentos e bebidas & 21 \\
\hline Economia & 20 \\
\hline Lazer & 18 \\
\hline Agenciamento & 16 \\
\hline Educação e formação & 16 \\
\hline Hospitalidade & 15 \\
\hline Anais de eventos & 14 \\
\hline História & 13 \\
\hline Transportes & 11 \\
\hline Turismo rural & 9 \\
\hline Animação e recreação & 8 \\
\hline Comunicação & 8 \\
\hline Geografia & 8 \\
\hline Sociologia & 8 \\
\hline Política & 6 \\
\hline Antropologia & 6 \\
\hline Metodologia científica & 6 \\
\hline Estatística & 4 \\
\hline Entretenimento & 3 \\
\hline Segmentação & 3 \\
\hline Psicologia & 3 \\
\hline Turismo religioso & 3 \\
\hline Contabilidade & 2 \\
\hline Ética & 2 \\
\hline Filosofia & 2 \\
\hline Terceira idade & 2 \\
\hline Turismo de aventura & 2 \\
\hline GLS & 1 \\
\hline Turismo urbano & 1 \\
\hline Outros & 9 \\
\hline
\end{tabular}

Fonte: dados da pesquisa 
A partir dos dados da Tabela 4 percebe-se que o tema meios de hospedagem é o que mais tem títulos publicados, seguido por um segundo grupo de temas composto por manuais, planejamento e desenvolvimento, administração/gestão e crítica e reflexão. Por outro lado, temas fundamentais como ética, filosofia e segmentação do mercado turístico apresentam poucos títulos. Portanto, em sua maioria os temas são genéricos e pouco específicos, o que, de certa forma, não contribui para o avanço do conhecimento na área.

Um campo de estudos, área temática ou ciência se fortalece a partir do momento em que surgem investigações profundas sobre temas específicos em suas áreas. Assim, a especialização leva à possibilidade de um maior e mais profundo conhecimento de aspectos não observados por análises genéricas, que não ajudam significativamente a fortalecer e a balizar a constituição de uma área ou ciência teórica.

$\mathrm{Na}$ categoria "outros", estão os temas: treinamento em qualidade, turismo: espaço e tempo, festividades, turismo e festa popular, trekking, organizações e turismo, turismo da juventude, turismo e financiamento, estatística e qualidade em serviços. Percebeu-se que quando mais segmentadas e específicas as temáticas, menor é a quantidade de livros.

Também foi analisado o número de autores por livro. O total de autores é de 573 , pois há os que escreveram ou organizaram mais de um livro. Os dados coletados foram os seguintes:

Livros publicados por apenas um autor - 396

Livros publicados por dois autores -81

Livros organizados -64

Livros publicados por três ou mais autores -32

Em $79,6 \%$ os livros são publicados por apenas um autor. Apenas 20,4\% dos livros são escritos por dois ou mais autores - isso somando os organizados.

Após os resultados de todas as análises supracitadas, sabe-se que ainda é possível analisar por outras perspectivas e de outras formas a produção bibliográfica em turismo no Brasil, assim como no mundo, visto que o mercado editorial brasileiro é apenas uma parte de todo o material da área do turismo. 


\section{Para Encerrar}

Numa possível comparação da área do turismo com outros campos e ciências, tais como a geografia, história, antropologia ou sociologia, ficaria latente a carência de publicações sobre esse assunto no Brasil. Mas essa consideração aplica-se somente ao Brasil. Caso façamos uma análise da publicação mundial poderíamos perceber que há um número relativo de material publicado sobre a temática desde o início do século XX. O entendimento desse problema passa pela compreensão do que o fenômeno turístico tem representado para o país com fonte de riquezas e de desenvolvimento humano e social. Também seria necessário um estudo abrangente do pensamento acadêmico brasileiro sobre o turismo e a busca do significado e do valor de um curso universitário com esse foco. Enfim, um estudo epistemológico que buscasse perscrutar a validade do conhecimento produzido, a maneira como é produzido esse conhecimento e a forma como ele é aplicado na vida prática é de extrema necessidade. Obviamente não é possível responder esse problema neste presente artigo.

Por limitações de tempo e de propósito da pesquisa, não foram identificadas as linhas teóricas dos livros analisados, nem avaliada a qualidade das publicações. Todavia acredita-se que os títulos com o maior número de edições ou tiragens são os melhores conceituados entre os leitores (ainda que as editoras que primeiro passaram a publicar em turismo são as que têm livros com número de edições mais altas, por motivos óbvios).

Conforme foi destacado nos estudos de Panosso Netto (2005 e 2007) as publicações em turismo aumentaram em número no Brasil durante a década de 1990 e mais especificamente nos anos de 2001, 2002 e 2003 devido ao público consumidor que estava crescendo, ou seja, alunos e professores universitários de turismo. Não foi um crescimento motivado pela importância que o turismo tem no contexto contemporâneo, mas muito mais pela visão dos editores que viram um meio de preencherem uma lacuna do mercado editorial que existia.

Frente aos dados analisados é premente a necessidade de fornecer subsídios e base teórica para estimular entre os pesquisadores o interesse pela compreensão e análise da produção científica nacional neste campo acadêmico.

Por fim, espera-se que com os dados atualizados e o aprofundamento da pesquisa a cena editorial do âmbito do turismo no Brasil fique mais clara, permitindo aos interessados 
conhecer e tirar suas próprias conclusões sobre as tendências do mercado do turismo e quais assuntos serão importantes ou obsoletos num futuro próximo.

\section{Referências}

BARRETTO, Margarita. 1996. Produção bibliográfica em turismo no Brasil. Turismo em Análise. São Paulo, v. 7, n. 2, p. 93-102.

BUFREM, Leilah e PRATES, Yara. 2005. O saber científico registrado e as práticas de mensuração da informação. Ci. Inf., Brasília, v. 34, n. 2, p. 9-25, maio/ago.

CALCIOLARI, Guilherme Farinazzo de Mello; PANOSSO NETTO, Alexandre. 2009. Análise da produção bibliográfica em turismo no Brasil (1990-2008). (Relatório final do Projeto Ensinar com Pesquisa). Escola de Artes, Ciências e Humanidades - EACH - Universidade de São Paulo - USP. São Paulo.

GUEDES, Vânia e BORSCHIVER, Suzana. 2005. Bibliometria: uma ferramenta estatística para a gestão da informação e do conhecimento, em sistemas de informação, de comunicação e de avaliação científica e tecnológica. In: Proceedings CINFORM - Encontro Nacional de Ciência da Informação VI, Salvador - Bahia.

MATTOS, Pedro Lincoln C. De L. 2004. "Bibliometria": a metodologia acadêmica convencional em questão. RAE-eletrônica, v. 3, n. 2, Art. 26, jul./dez. 2004. Disponível em: $<$ http://www.rae.com.br/eletronica/index.cfm?FuseAction=Artigo\&ID=2199\&Secao=DEBATE\&Vol ume $=3 \&$ Numero $=2 \& A n o=2004>$.

PANOSSO NETTO, Alexandre. 2007. Análise da produção bibliográfica de turismo do Brasil - 19902007. Anais. IV Seminário da Associação Brasileira de Pesquisa e Pós-Graduação em Turismo UAM27 a 28 de agosto.

2005. Publicações em turismo no Brasil. In: TRIGO, Luiz Gonzaga Godoi et. al. Análises regionais e globais do turismo brasileiro. São Paulo: Roca, 2005, p. 257-273.

SANTOS, Raimundo Nonato Macedo dos; KOBASHI, Nair Yumiko. 2009. Bibliometria, cientometria, infometria: conceitos e aplicações. Pesq. bras. Ci. Inf., Brasília, v.2, n.1, p.155-172, jan./dez.

VALLE, Maristela do. 2002. Mercado editorial de turismo vive boom. In: Folha de São Paulo. São Paulo, 29 de abril de 2002. Disponível em: <http://www1.folha.uol.com.br/folha/turismo/noticias/ ult338u1725.shtml $>$. Acesso em 27 de agosto de 2010.

VANTI, Nadia Aurora Peres. 2002. Da bibliometria à webometria: uma exploração conceitual dos mecanismos utilizados para medir o registro da informação e a difusão do conhecimento. Ci. Inf., Brasília, v. 31, n. 2, p. 152-162, maio/ago.

Recebido em: 06/10/2009 (1 ${ }^{\mathrm{a}}$ versão) 02/09/2010 ( $2^{\mathrm{a}}$ versão)

Aprovado em: 09/11/2010 


\section{Apêndice}

\section{Sites gerais}

www.inep.gov.br/superior/censosuperior/sinopse/

www.bn.br

www.livrosdeturismo.com.br

www.mjlivros.com.br

\section{Sites das editoras}

www.afe.com.br

www.almedina.com.br

www.atica.com.br

www.atomoealinea.com.br

www.autenticaeditora.com.br

www.bookman.com.br

www.campus.com.br

www.casadaqualidade.com.br

www.contracapa.com.br

www.edfutura.com.br (Página não disponível)

www.edicon.com.br

www.edipro.com.br

www.editora.ucdb.br

www.editora.ufscar.br

www.editora.unb.br

www.editoraaleph.com.br

www.editoraanhembi.com.br

www.editoraatlas.com.br

www.editoracabral.com.br

www.editoracontexto.com.br

www.editorarenovar.com.br

www.editoraroca.com.br 
www.editoratextonovo.com.br

www.editoraufmg.com.br

www.editoraverbo.com.br

www.edufba.ufba.br

www.erica.com.br

www.garamond.com.br

www.hucitec.com.br

www.iconeeditora.com.br

www.jurua.com.br

www.letrasjuridicas.com.br

www.livrariavaler.com.br

www.manole.com.br

www.mundoeducacaofisica.com/livros

www.papirus.com.br

www.pearson.com.br

www.protexto.com.br

www.qualitymark.com.br

www.rimaeditora.com.br

www.saraivauni.com.br

www.senac.br/livrariavirtual

www.sp.senac.br

www.thomsonlearning.com.br

www.ucs.br

www.uniasselvi.com.br

www.unisc.br/edunisc

www.univercidade.edu

www.usc.br 